\title{
An Improved $\mathbf{P I}^{\lambda}$ Controller for Resonant Inverter Induction Heating Systems under Load and Line Variations
}

\author{
M. HELAIMI ${ }^{1}$, M. BENGHANEM ${ }^{2}$, B. BELMADANI ${ }^{3}$ \\ ${ }^{1,3}$ Department of Electrical Engineering, University Hassiba Ben Bouali, \\ Chlef, Algeria, \\ halimi1976@yahoo.fr \\ 2 Department of Automatic Control, \\ University of Mohamed Boudhiaf \\ Oran, Algeria
}

\begin{abstract}
This paper presents the description, analysis and control of an LLC resonant inverter suitable for induction heating applications. The output power of the proposed inverter has to be controlled by adjusting the duty cycle of the switches using a power loop circuit based on fractional order $\mathrm{PI}^{\lambda}$ controller. A phased locked loop (PLL) is used as frequency tracking control circuit. The complete closed loop control model is obtained using small signal analysis. The validity of the proposed control is verified by simulation results. Results of this simulation are compared to those obtained by using a PI controller. They show that the improved $\mathrm{PI}^{\lambda}$ controller exhibits a much better behaviour.
\end{abstract}

Keywords: Robustness, LLC resonant inverter, small signal model, improved $\mathrm{PI}^{\lambda}$ controller, induction heating system.

\section{Introduction}

Nowadays, resonant topologies are used in a number of industrial applications, including power supplies for induction heating systems. LLC is being a more popular topology because it has the desirable characteristics of the series and parallel ones [1]-[5].

In control practice, fractional order $\mathrm{PI}^{\lambda}$ controllers have been successfully applied to a wide variety of engineering problems [6]-[13], including DC-DC converters [14].

Several research works on control theory reveal that the design of the $\mathrm{PI}^{\lambda}$ controller is not easy when the system is difficult to model due to complexity, non linearity, or when the resource of information are inexact. LLC resonant inverters fall into this category because they have a time varying structure and contain elements that are non linear.

In this paper, we propose an effective control system for LLC resonant inverter which uses variable frequency and variable duty cycle. The output power of the proposed inverter has to be controlled by adjusting the duty cycle of the switches using power loop circuit based on fractional order PI $\lambda$ controller. A PLL is used as frequency tracking control. In this case, a stability and small signal dynamic performance can be assessed using linear control techniques and the small signal model of the LLC resonant inverter.

The organization of this paper is as follows: the proposed inverter circuit configuration and the detailed control system architecture are given in Sections II and III. Closed loop system design and parameter tuning of the proposed $\mathrm{PI}^{\lambda}$ controller are presented in Sections IV. Conclusion is given in Section V.

\section{Circuit Description}

A number of induction-heating resonant inverters have been reported in literature. However, they all employ the basic conversion process of AC-DC rectification of the phase source and followed by a single phase higher frequency stage. Figure 1 show the proposed configuration used in this work:

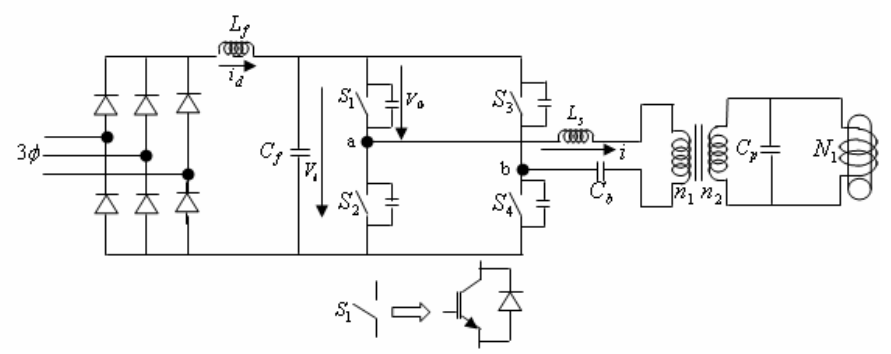

Figure 1. The proposed LLC resonant inverter 


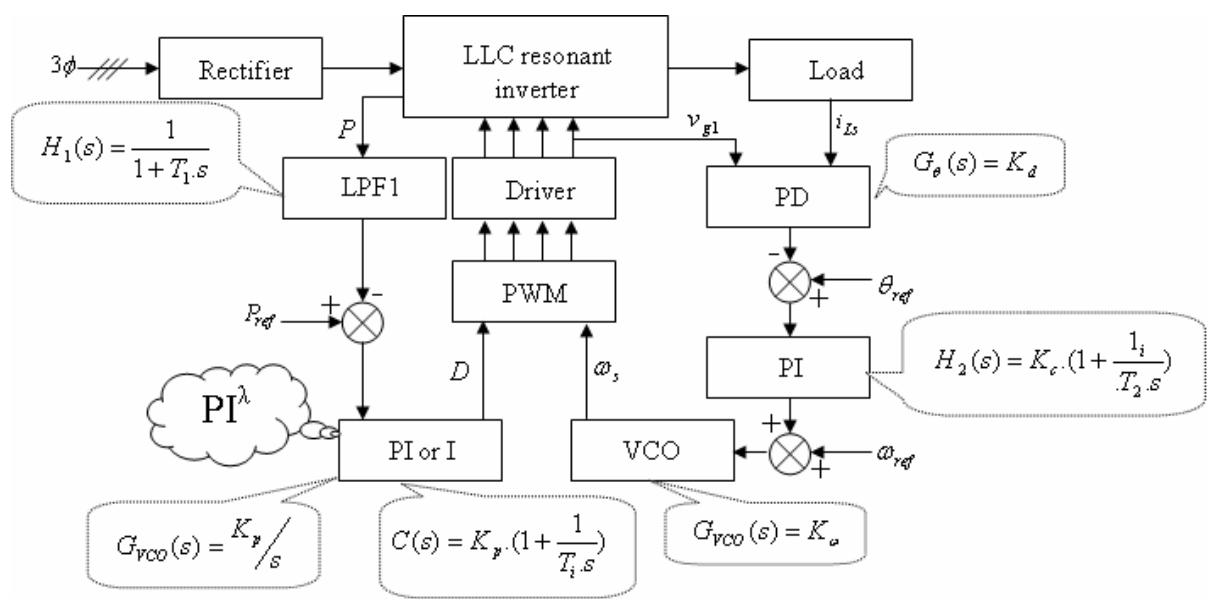

Figure 2. Detailed closed loop system architecture

It consists of four IGBT transistors with antiparallel diodes and the resonant tank LLC. The transistors S1 and S4 conduct alternately to S2 and S3 with a duty of $50 \%$. The induction heating load constitutes a $50 \mathrm{CrV} 4$ carbon steel billet placed inside a N1-turns cooper coil at specific air gap.

The induction heating load can be modelled by means of a series combination of its equivalent resistance and equivalent inductance [15]-[16].

\section{Proposed Control System}

Figure 2 describes detailed complete closed loop system architecture. The output power of the resonant inverter has to controlled by adjusting the duty cycle of the IGBT using power loop circuit based on simple integrator $\mathbf{I}$ controller or PI controller [17]-[18]. A PLL is used as frequency tracking control circuit.

In this paper, we propose an effective power loop circuit based on fractional order $\mathrm{PI}^{\lambda}$ controller.

\section{Closed Loop System Design}

Figure 3 shows the simplified form of the complete closed loop configuration given is previous section:

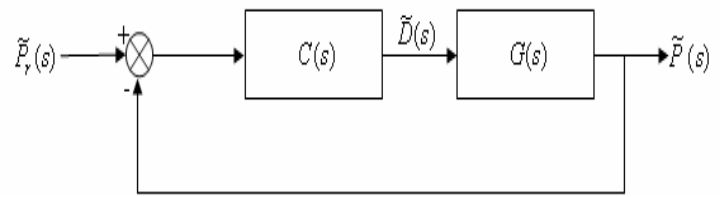

Figure 3. Unitary feedback configuration

$C(s)$ is the controller to implement, $G(s)$ is the plant to be controlled.

\section{a. Open Loop Small Signal Circuit}

Under the assumptions given in [19], the circuit of Figure 1 with the proposed control can be reduced to simplified form of Figure 4:

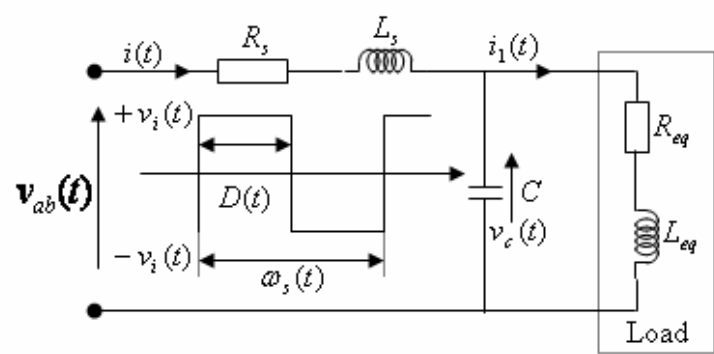

Fig.4: simplified form of the LLC resonant inverter

Kirchhoff's voltage law is applied to the circuit in Figure 6 to give:

$$
\left\{\begin{array}{l}
\operatorname{sign}(\mathrm{i}) v_{a b}(t)=R_{s} \cdot i(t)+L_{s} \cdot \frac{d i(t)}{d t}+v_{c}(t) \\
v_{c}(t)=R_{e q} \cdot i_{1}(t)+L_{e q} \cdot \frac{d i_{1}(t)}{d t} \\
C . \frac{d v_{c}(t)}{d t}=i(t)-i_{1}(t)
\end{array}\right.
$$

The state space variables are defined as the inductor currents and capacitor voltage:

$$
x(t)=\left[i(t) \quad v_{c}(t) \quad i_{1}(t)\right]^{t}
$$

The input variables are implicitly included in input voltage $v_{a b}(t)$ :

$u(t)=\left[D(t) \quad \omega_{s}(t)\right]^{t}$

And the output variable is the output power:

$P(t)=\frac{1}{2} \cdot R_{e q} \cdot i_{1}^{2}(t)$ 


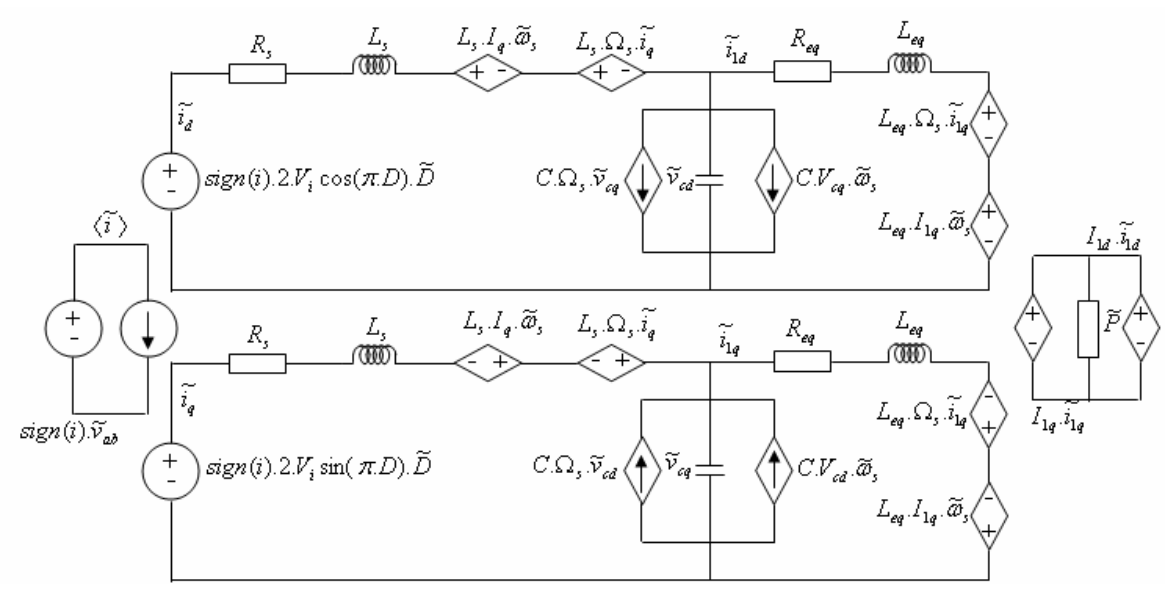

Figure 5. Small signal circuit of the LLC resonant inverter
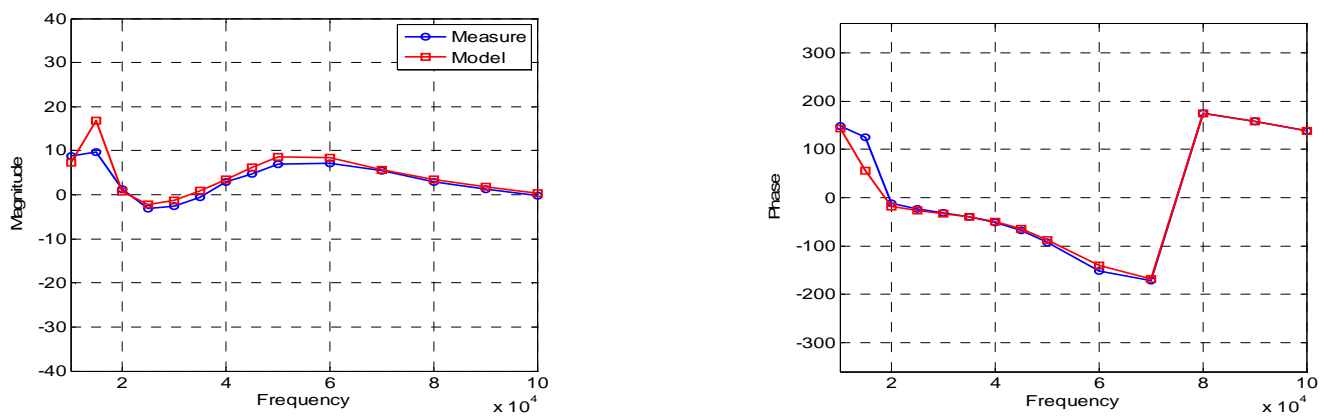

Figure 6. Validation of the small signal circuit $\tilde{P}(t)$ to $\tilde{\omega}_{s}(t)$
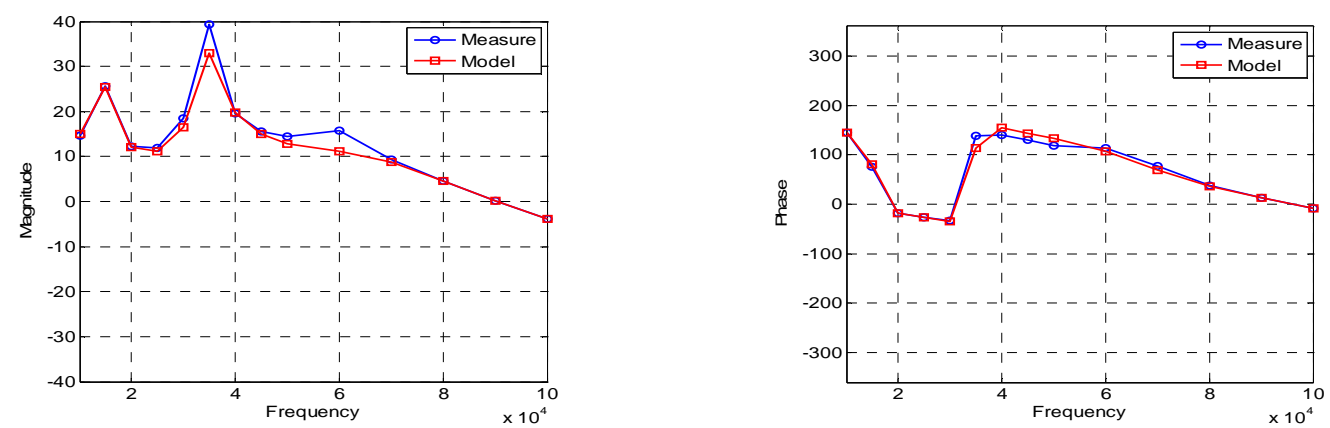

Figure 7. Validation of the small signal circuit $\widetilde{P}(t)$ to $\tilde{D}(t)$

There have been several approaches reported in literature to get small signal modelling. In this paper, the small signal circuit of the LLC resonant inverter is obtained using the EDF technique [20]-[23]. In this approach, the nonlinear model given in (1) is used by decomposing $i(t), v_{c}(t)$ and $i_{1}(t)$ into $d$ and $q$ waveforms, and then harmonic balance are performed, by which the large signal model can be derived. The small signal circuit represented in Figure 5 is derived by perturbation and linearization of large signal model around the operating point where:

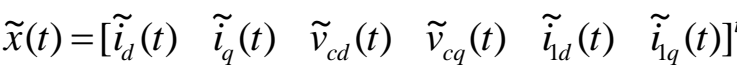

$$
\begin{aligned}
& \tilde{u}(t)=\left[\begin{array}{ll}
\tilde{D}(t) & \tilde{\omega}_{s}(t)
\end{array}\right]^{t}, \tilde{y}(t)=\tilde{P}(t)
\end{aligned}
$$

The system parameters are:

$$
\begin{aligned}
& R_{s}=0.187 \Omega, L_{s}=3.2 \mu \mathrm{H}, R_{e q}=0.355 \Omega \\
& f_{s}=120 \mathrm{kHz} L_{e q}=0.93 \mu \mathrm{H}, \\
& C=1.8 \mu \mathrm{F}, V_{i}=12 v, D=0.5,
\end{aligned}
$$

To verify the above analysis and calculation, Figures 6 and 7 show the validity of the derived small signal circuit. 
There is a certain deviation between the theoretical small signal circuit model and measure circuit results. The reason is that only the fundamental component is considered in the modeling approach.
The phase margin is positive and equal to $145.62^{\circ}$.

\section{b. Conventional PI controller}

The ideal transfer function of PI controller has the following form (6):

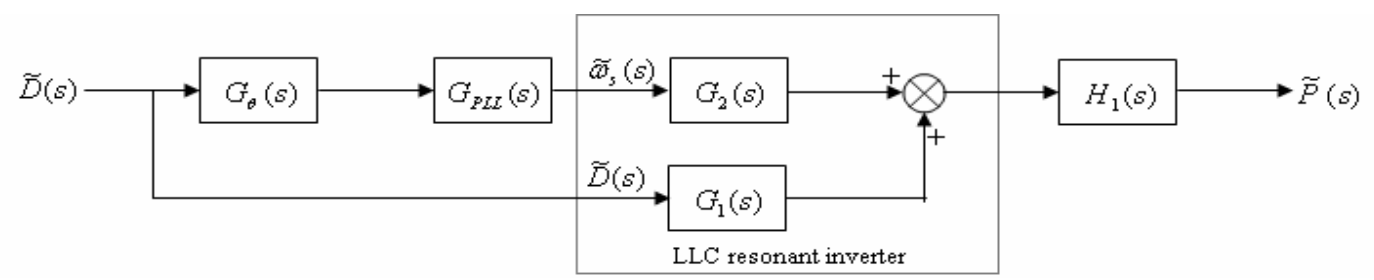

Figure 8. Bloc diagram of the open loop $G(s)$

Using the small signal circuit we can get the bloc diagram of the system to be controlled, as shown in Figure 8 where:

$G(s)=\left(G_{\theta}(s) \cdot G_{P L L}(s) \cdot G_{2}(s)+G_{1}(s)\right) \cdot H_{1}(s)(5)$

$G_{\theta}(s), G_{P L L}(s)$ and $H_{1}(s)$ are given in section III.

The pole of $G(s)$ are found to be:

$$
\begin{aligned}
& p_{1,2}=(-0.1693 \pm 1 \cdot 6338 \cdot i) \cdot 10^{6}, \\
& p_{3,4}=(-0.1376 \pm 0.7525 \cdot i) \cdot 10^{6} \\
& p_{5,6}=(-0.1693 \pm 0.1285 \cdot i) \cdot 10^{6}, \\
& p_{7}=-0.7527 \cdot 10^{6}
\end{aligned}
$$

Where $K_{p}$ and $T_{i}$ are the proportional gain and the integral time constant.

The set of variables $K_{p}$ and $T_{i}$ are the parameters to be tuned.

In this work, we adopted the minimization of the integral square error ISE, which is defined as:

$$
J\left(K_{p}, T_{i}\right)=\int_{0}^{\infty} e^{2}(t) d t
$$

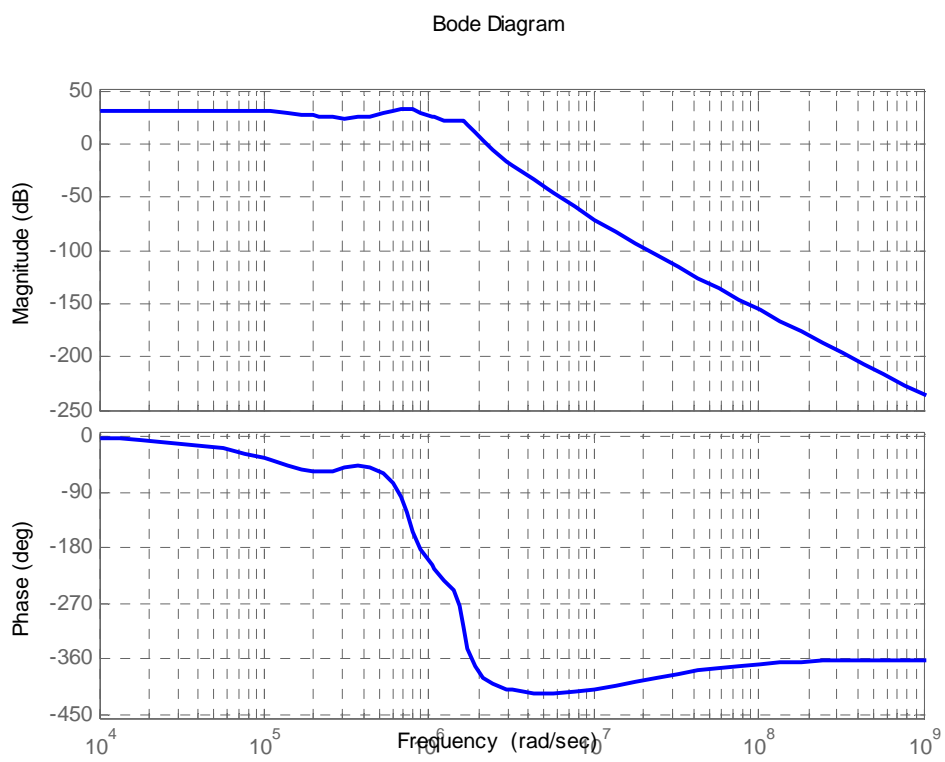

Figure 9. bode plot of the open loop $G(s)$

Notice that all the real parts of the poles are negatives, thus, the system is found stable.

The bode plot of the open loop transfer function is shown in Figure 9:
Subject to,

$$
K_{p}>0 \text { and } T_{i}>0
$$

The controller parameters are: 
$K_{p}=0.0195, T_{i}=20.10^{-6}$.

\section{c. Fractional order $\mathbf{P I}^{\lambda}$ controller}

The second controller we investigated is the fractional order $\mathrm{PI}^{\lambda}$ controller with the transfer function given by (9):

$$
C(s)=K_{p F} \cdot\left(1+\frac{1}{T_{i F} \cdot s^{\lambda}}\right)
$$

Three parameters can be tuned in this structure $K_{p F}, T_{i F}$ and $\lambda$ that is an additional parameter.

There are several approaches that been used to implement fractional order controller. In this application, the fractional order integral has been implemented by using Oustaloup's frequency approximation method described in [24].

Over the years, many formulas for optimum design of the controllers have published. One common approach is to minimize a general performance index given by (10):

$$
J=w_{1} \cdot \int_{0}^{\infty} t^{\alpha} \cdot|e(t)|^{\beta} \cdot d t+w_{2} \cdot \int_{0}^{\infty} u^{2}(t) \cdot d t
$$

Common cases include

$\operatorname{IAE}\left(\alpha=0, \beta=1, w_{1}=1, w_{2}=0\right)$

ISE $\left(\alpha=0, \beta=2, w_{1}=1, w_{2}=0\right) \quad$ or $\left(\alpha=0, \beta=2, w_{1}=1, w_{2}=1\right)$

ITSE ( $\left.\alpha=1, \beta=, w_{1}=1, w_{2}=0\right)$

Kristansson and Lannartson [25] have defined another performance criterion in frequency domain formulated as:

$$
J=\max _{\omega}\left|\frac{1}{j . \omega} \cdot \frac{G(j . \omega)}{1+G(j . \omega) \cdot C(j . \omega)}\right|
$$

For getting good dynamic performance and avoiding large control effort, we introduce the control activity criterion $J_{u}$ defined as:

$$
J_{u}=\max _{\omega}\left|\frac{C(j . \omega)}{1+G(j . \omega) . C(j . \omega)}\right|
$$

The procedure to determine the $\mathrm{PI}^{\lambda}$ controller parameters are summarized in the following:

1. The initial rang of parameters are selected to be:

$K_{p F} \in[0,10], T_{i F} \in[0,10]$ and $\lambda \in[0,1]$

2. Find parameters of the controller that minimize the performance criterion (11) subject to control activity criterion (12)

3. Using Oustaloup approximation to get a rational function in the frequency band $\left[10^{0} \mathrm{rad} / \mathrm{s}, 10^{6} \mathrm{rad} / \mathrm{s}\right]$

The optimized parameters of the fractional $\mathrm{PI}^{\lambda}$ controller are: $K_{p F}=0.5665, K_{i F}=0.2$ and $\lambda=0.2$

\section{Comparison and Discussion}

In this section, we evaluate, through computer simulation performed

in

MATLAB/SIMULINK, the ability of the

Bode Diagram

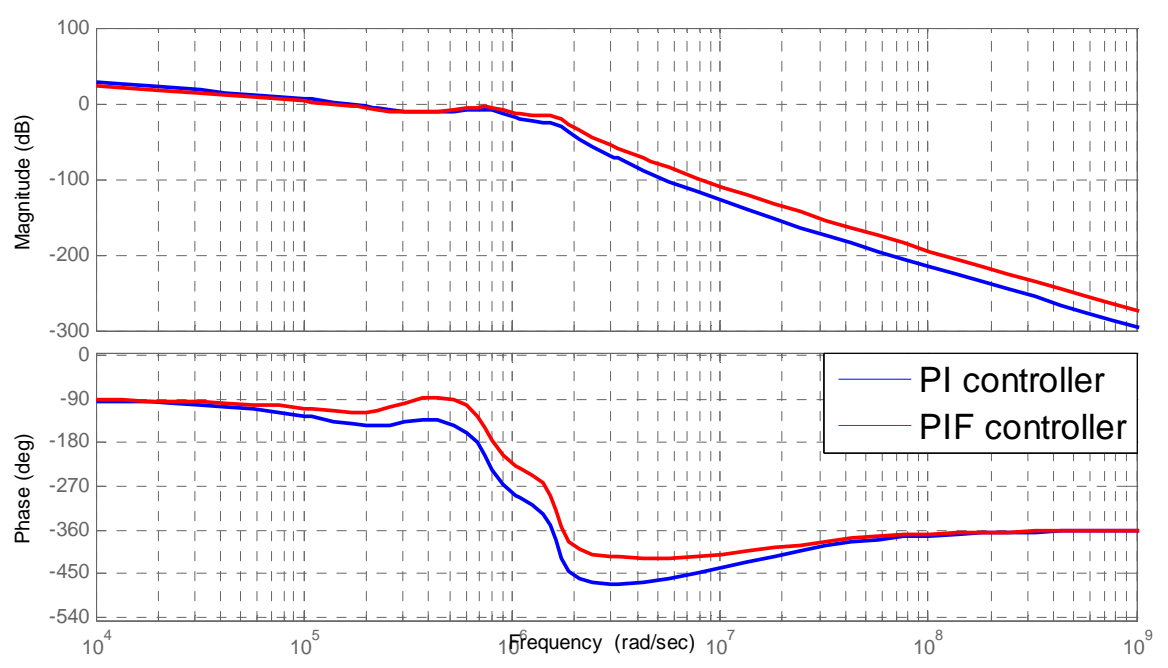

Figure 10. Bode plots of the open loop transfer function with $\mathrm{PI}$ and $\mathrm{PI}^{\lambda}$ 
proposed controller to regulate the output power of the system modelled in IV.1.

The control objectives are:

1. To heat steel metal from $20^{\circ} \mathrm{C}$ to $240^{\circ} \mathrm{C}$ in $15 s$.

2. To regulate the output power.

3. To maintain power factor near unity

$\mathbf{1}^{\text {st }}$ comparison: step response

Figure 10 shows the Bode plots of the open loop transfer function $L(s)=C(s) \cdot G(s)$ with both the conventional PI and the fractional $\mathrm{PI}^{\lambda}$ controllers. The LLC responses are shown in Figure 11.

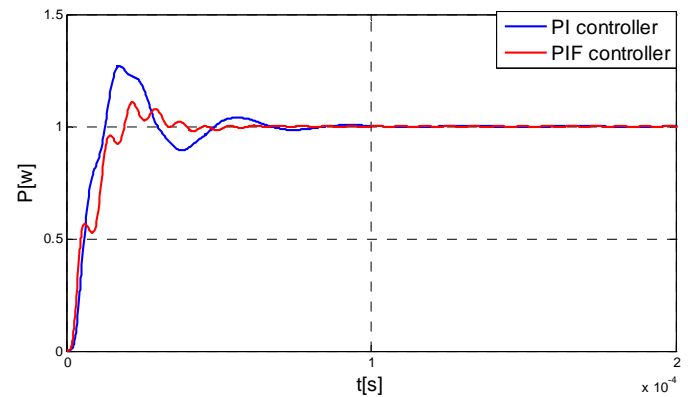

Figure 11. Step response of the non linear model with $\mathrm{PI}$ and $\mathrm{PI}^{\lambda}$

Some performance characteristics for the feedback control systems with the two proposed controllers are summarized in Table I:

Table I. Some performance characteristics

\begin{tabular}{|l|c|c|c|}
\hline & $\begin{array}{c}\text { Phase } \\
\text { margin } \\
{\left[{ }^{\circ} \text { ] }\right.}\end{array}$ & $\begin{array}{c}\mathbf{I}_{1 \max } \\
\text { [A] }\end{array}$ & $\begin{array}{c}\text { Overshoot } \\
{[\%]}\end{array}$ \\
\hline $\mathrm{G}(\mathrm{s})$ & 145.62 & - & - \\
\hline $\begin{array}{l}\text { PI } \\
\text { Controller }\end{array}$ & 39.46 & 12.993 & 27.03 \\
\hline $\begin{array}{l}\mathrm{PI}^{\lambda} \\
\text { Controller }\end{array}$ & 66.48 & 11.6159 & 10.79 \\
\hline
\end{tabular}

By examine those results, it can said that when the control parameters of the PI controller are chosen for achieving fast response, the overshoot is relatively large ( $27.03 \%)$.

Another interesting result is that the LLC resonant inverter does not consume more current in the fractional case.

$2^{\text {nd }}$ comparison: robustness to load variation

Robustness is an important consideration in control design. The tradeoff between the robustness and performance must be taken into account when comparing the performance of different control structures. To study the system robustness we introduce a variation of $\pm 30 \%$ of $R_{e q}$ in the nominal plant. The results obtained are presented in Figure 12 and 13, respectively:

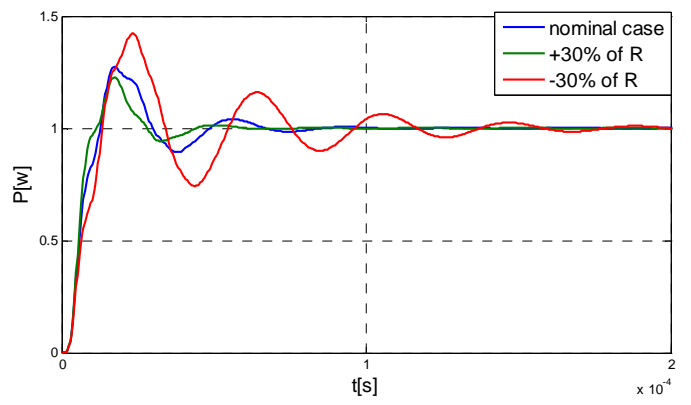

Figure 12. Step response of the closed loop system using conventional PI

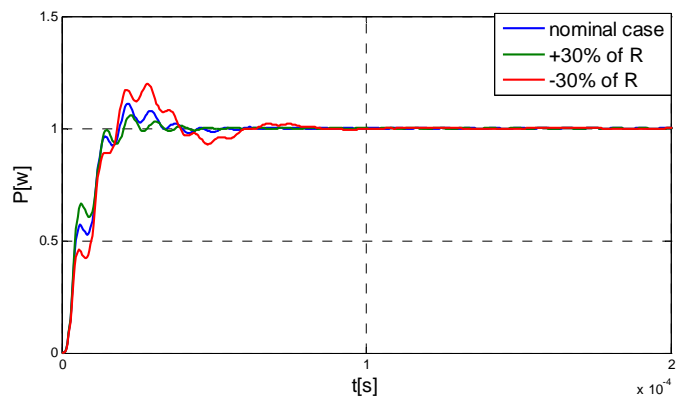

Figure 13. Step response of the closed loop system using $\mathrm{PI}^{\lambda}$ controller

Figure 15 demonstrate the robustness of the $\mathrm{PI}^{\lambda}$ controller to $\pm 30 \%$ of $R_{e q}$.

$3^{\text {rd }}$ comparison: robustness to line variation

To show the controller robustness with respect to line variation $V_{i}$ is varied, with $20 \%$ lower and $20 \%$ higher than its nominal value $12 v$.

Figures 14 and 15 show the time response with the corresponding PI controller as well as the response of $\mathrm{PI}^{\lambda}$ controller:

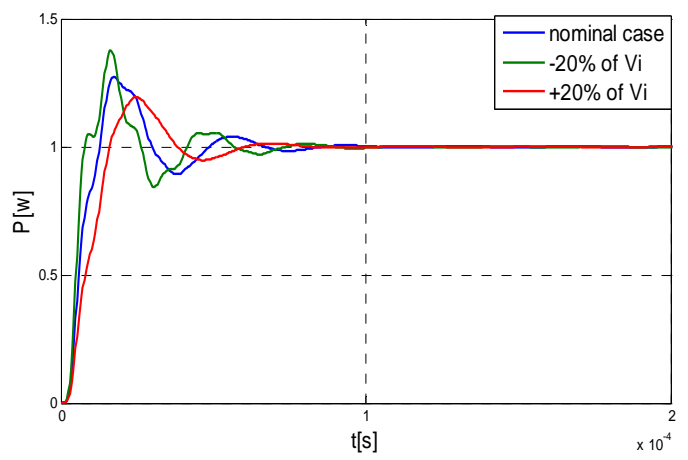

Figure 14. Step response of the closed loop system using PI controller 


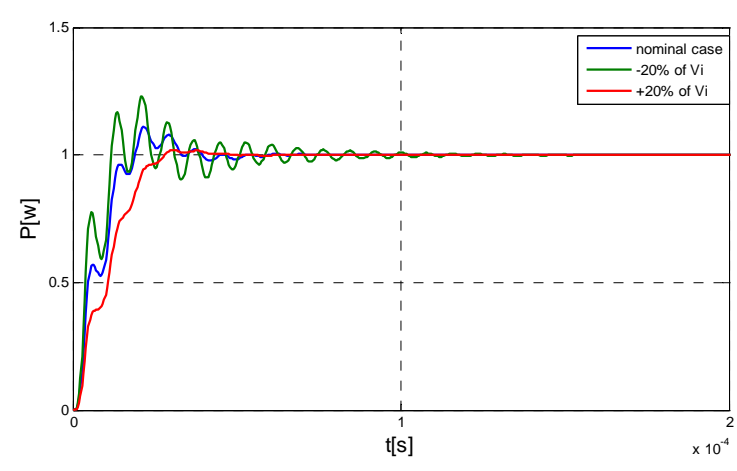

Figure 15. step response of the closed loop system using $\mathrm{PI}^{\lambda}$ controller

It is important to note that the $\mathrm{PI}^{\lambda}$ control system gives the better overall response compared to the PI controller.

\section{Conclusion}

The design and implementation of $\mathrm{PI}^{\lambda}$ controller for the closed loop power regulation of LLC resonant inverter is discussed in this paper. The effectiveness of the proposed controller as compared with PI is verified by simulation studies. It is proved that the $\mathrm{PI}^{\lambda}$ has the ability to regulate the output power against load disturbances faster than the PI thereby reducing the settling time and the overshoot. The proposed $\mathrm{PI}^{\lambda}$ controller can be effectively implemented for other inverter topologies or complex structured nonlinear systems controlled using DSP processor or FPGA.

\section{REFERENCES}

1. CHUDJUARJEEN, S., A. SANGSWANG, C. KOOMPAI, An Improved LLC Resonant Inverter for Induction-Heating Applications with Asymmetrical Control, IEEE Transactions on Industrial Electronics, vol. 58(7), July 2011, pp. 2915-2925.

2. CHUDJUARJEEN, S., V. HATHAIRATSIRI, Series and Parallel Resonant Inverter for Induction Heating application, International Conference on Science, Technology and Innovation for Sustainable Well-Being (STISWB), 23-24 July 2009, Mahasarakham University, Thailand.

3. KELEMEN, A., N. KUTASI, Lyaponovbased Frequency Shift Power Control of Induction Heating Converters with Hybrid Resonant Load, Acta Universitatis Sepientiae, 2009, pp. 41-52.
4. EPSI, J., E. DEDE, R. G. GIL, J. C. MORENO, Design of the L-LC Resonant Inverter for Induction Heating based on its Equivalent SRI, IEEE Transactions on Industrial Electronics, vol. 54, $\mathrm{N}^{\circ} 6$, December 2007, pp. 3178-3187.

5. CHUDJUARJEEN, S., A. SANGSWANG, C. KOOMPAI, LLC Resonant Inverter for Induction Heating with Asymmetrical Voltage-Cancellation Control, in Proc. IEEE Int. Symp. Circuits Syst., Taipei, Taiwan, May 2009, pp. 2874-2877.

6. MANSOURI, R., S. DJENOUNE, $M$. BETTAYEB, Fractional I-P Pole Placement Controller Design: Application To Permanent Magnet Synchronous Motor Control, Int. J. Modelling, Identification and Control, vol. 4, N², 2008, pp. 176-185 [Online].

7. BETTOU, K., A. CHAREF, Control Quality Enhancement Using Fractional $\mathbf{P I} \lambda \mathbf{D} \boldsymbol{\mu}$ Controller, Int. Journal of Sciences and Systems, vol. 40, N8, August. 2009, pp. 875-888.

8. PODLUBNY, I., Fractional Order Systems and Fractional Order Controllers, Inst. Exp. Phys., Slovak Acad. Sci., Vol.4, No.2, 1994, pp.28-34.

9. CHAREF A., Analogue Realization of Fractional Order Integrator, Differentiator and Fractional PI $\lambda D \boldsymbol{\mu}$, IEEE Proceeding on Control Theory Applications, vol. 54, N5, 2006, pp. 714-720.

10. FONSECA, N. M., J. A. TENREIRO, Fractional-order hybrid control of Robotic Manipulators. In 11th Intl. conference on advanced robotics, Coimbra, Portugal, 2003, pp. 393-398.

11. LAROCHE, E., D. KNITTEL, An Improved Linear Fractional Model for Robustness Analysis of a Winding System, Control Engineering Practice, 13(5), 2005, pp. 659-666.

12. PETRAS, I., B. M. VINAGRE, L. DORCAK, V. FELIU, Fractional Digital Control of a Heat Solid: Experimental Results, In International Carpathian control conference, Malenovice, Czech Republic, 2002, pp. 365-370.

13. MONJE, C. A., B. M. VINAGRE, V. FELIU, Y. Q. CHEN. Tuning and Auto- 
Tuning of Fractional Order Controllers for Industry Applications, Control Engineering Practice 16, 2008, pp. 798-812.

14. CALDERON, A. J., B. V. VINAGRE, V. FELIU, Buck-Boost Converter with Fractional Control of Electric Vehicles, International Conference on Renewable Energies and Power Quality, Granada Spain, 23rd to 25th March, 2010.

15. AHMED, N. A., Three-phase High Frequency AC Conversion Circuit with Dual Mode PWM/PDM Control Strategy for High Power IH Applications, PWASET Vol. 35, November 2008, pp. 371-377.

16. LUCÍA, O., J. M. BURDIO, I. MILLÁN, J. ACERO, D. PUYAL, Load-adaptive Algorithm of Half-bridge Series Resonant Inverter for Domestic Induction Heating, IEEE Transactions on Ind. Electron., vol. 56, No. 8, Aug. 2009, pp. 3106-3116.

17. TIAN, J., J. PETZOLDT, T. RIEMANN, M. SCHERF, G. BERGER, Control System Analysis and Design of a Resonant Inverter with the Variable Frequency Variable Duty Cycle Scheme, European Conference on Power Electronics and Applications, 2005, Dresden, Germany.

18. LUCÍA, O., J. M. BURDIO, I. MILLÁN, J. ACERO, L. A. BARRAGÁN, Efficiency oriented Design of ZVS Half-bridge Series Resonant Inverter with Variable Frequency Duty Cycle Control, IEEE Trans. Power Electron., vol. 25, Nº. 7, Jul. 2010, pp. 1671-1674.

19. KAMLI, M., S. YAMAMOTO, M. ABE, A $50-150 \mathrm{Khz}$ Half-bridge Inverter for Induction Applications, IEEE Transactions on Industrial Electronics, vol. 43, Nº1, Feb. 1996, pp. 163-172.
20. YANG, E. X., F. C. LEE, M. M. JOVANOVIC, Small Signal Modeling of Power Electronic Circuits using Extended Describing Function Technique, in Proc. VPEC, 1991, pp. 167-178.

21. MARTIN-RAMOS, J. A., J. DIAZ, A. M. PERNIA, J. M. LOPERA, F. NUNO, Dynamic and Steady State Models for the PRC-LCC Resonant Topology with a Capacitor as Output Filter, IEEE Transactions on Industrial Electronics, vol 54, N²4, August 2007, pp. 2262-2274.

22. GRAJALES, L., F.,C. LEE, Control system Design and Small Signal Analysis of a Phase Shift Controlled Series Resonant Inverter for Induction Heating, in PESC Record- IEEE Power Electronics Specialists Conference, 1995, pp. 450-456.

23. TIAN, J., J. PETZOLDT, T. REIMANN, M. SCHERF, G. BERGER, Modelling of Asymmetrical Pulse Width Modulation with Frequency Tracking Control using Phasor Transformation for Half-Bridge Series Resonant Induction Cookers, 11th European Conference on Power Electronics and Applications (EPE), September, 2005, Dresden, Germany.

24. GAO, Z., X. LIAO, Improved Oustaloup Approximation of Fractional-order Operators using Adaptive Chaotic Particle Swarm Optimization, Journal of Systems Engineering and Electronics, Vol. 23, No 1, Feb. 2002, pp. 145-153 .

25. KRISTIANSSON, B., B. LENNARSTON, Robust and Optimal Tuning of PI and PID Controllers, IEE Proceedings of Control and Applications, Vol. 149, $\mathrm{N}^{\circ} 1$, 2002, pp. 17-25. 